УДК 744:004.92

\title{
МЕТОДИКА ФОРМИРОВАНИЯ ЛОГИЧЕСКИХ СВЯЗЕЙ ИНЖЕНЕРНОЙ ГЕОМЕТРИИ ИЗДЕЛИЯ
}

Шоркина Ирина Николаевна старший преподаватель Анисимова Нина Анатольевна к.т.н., доцент ФГБОУ ВО «Волжский государственный университет водного транспорта»

\begin{abstract}
Аннотация: Данная статья является следствием экспериментального внедрения методики проведения лабораторных работ по дисциплине «Инженерная и компьютерная графика», проводимых кафедрой «Теории конструирования инженерных сооружений». Предлагается к рассмотрению новая методика, построенная для геометрической интерпретации логических связей между инженерными понятиями. Рассмотренные вопросы создания электронной модели изделия, построенные на логических связях с эскизом и ассоциативным чертежом, позволили решить поставленные цели методики графо - геометрической подготовки будущего специалиста. В ходе экспериментального применения получены статистические результаты эффективности. Полученные данные, позволили ввести корректировку в рабочие программы дисциплины.
\end{abstract}

Ключевые слова: Изделие, инженерная и компьютерная графика, САПР, логические связи, эскиз, геометрическая модель, чертеж, трехмерное моделирование, компетенции, инженерная геометрия.

\section{TECHNIQUE FOR FORMING LOGICAL LINKS OF ENGINEERING GEOMETRY OF THE PRODUCT}

\section{Shorkina Irina Nikolaevna Anisimova Nina Anatolievna}

\begin{abstract}
This article is a consequence of the experimental implementation of laboratory work methods in the discipline "Engineering and Computer Graphics",
\end{abstract}


conducted by the Department of "Theory of Engineering Structures Design". A new technique is proposed for consideration, built for the geometric interpretation of logical connections between engineering concepts. The considered issues of creating an electronic model of a product, built on logical connections with a sketch and an associative drawing, made it possible to solve the set goals of the methodology - graphic - geometric training of a future specialist. In the course of experimental use, statistical results of efficiency were obtained. The data obtained made it possible to introduce an adjustment into the work programs of the discipline.

Key words: Product, engineering and computer graphics, CAD, logical connections, sketch, geometric model, drawing, three-dimensional modeling, competencies, engineering geometry.

Актуальность. В настоящее время 3D - проектирование является важнейшим компонентом при создании современных изделий машино - и судостроении, позволяет в реальном времени проверить адекватность альтернативных конструкций, когда необходимо учитывать множество требований к изделию.

Развитие у обучающихся объемного представления объектов дает стартовый толчок к пониманию конструкторской деятельности. Курс инженерной и компьютерной графики обеспечивает многоуровневый методический комплекс, дающий возможность студентам нарабатывать инженерные навыки, используя инструменты плоскостного и трехмерного моделирования систем автоматизированного проектирования (САПР).

Теоретическое обоснование. В 2016 году преподавателями кафедры «Теории конструирования инженерных сооружений» в курс «Инженерной и компьютерной графики» были введены лабораторные работы по созданию электронной модели изделия, построенные на логических связях с эскизом и ассоциативным чертежом. Для установления эффективности применения новой методики были зафиксированы результаты пятилетней работы.

Целью исследования стала разработка методики формирования у обучающихся:

- способности к обобщению, анализу, восприятию графической информации;

- развитию пространственного мышления; 
- освоение методов наглядного изображения и моделирования трехмерных форм.

\section{Задачи новой методики:}

- формирование у обучающихся комплекса навыков и компетенций в соответствии с федеральным государственным образовательным стандартом высшего образования (ФГОС ВО);

- отражение современных достижений науки;

- последовательная реализация логических связей в практическом применении;

- совершенствование технологии обучения.

Современная модель образования проектируется и практически реализуется на основе методологических подходов, которые, в свою очередь, взаимодействуют и дополняют друг друга.

Методологической основой $[1,2]$ реализации новых внедрений являются:

- системно - деятельностный подход, который дает понимание образовательного процесса как совокупности многообразных взаимосвязанных и взаимообусловленных видов деятельности всех задействованных в нем субъектов;

- компетентностный подход, который определяет практикоориентированность педагогического процесса, развивает у обучающихся способности к самостоятельному принятию решений на основе полученного жизненного и профессионального опыта;

- личностный подход означает помощь обучающемуся в самореализации и развитии личности.

Представленная новая методика ориентируется на современное образование, направленное на формирование компетенций, предполагает создание дидактических и психологических условий, в которых студент может проявить не только интеллектуальную и познавательную активность, но и личностную социальную позицию, выразить себя как субъект обучения [3]. Психолого-педагогической основой является активная познавательная деятельность самого студента, приводящая к формированию умений творчески мыслить, используя приобретаемые в процессе деятельности знания, навыки и умения. 
Эксперимент. Практическая часть, реализуемой методики, состояла из лабораторных работ, которые формировались по восходящей схеме «от простого к сложному». Лабораторные работы направлены на освоение студентами тематического материала 3 этапами:

- эскизирование деталей судовой арматуры по реальной детали,

- создание трехмерной геометрической модели по эскизу изделия,

- построение полуавтоматического чертежа изделия по модели.

Структура методики завязана на посторенние логических связей восприятия материала у обучающихся. Визуально такие связи можно отобразить в виде структурной схемы, представленной на рисунке 1 , изображающей взаимосвязанные множества. Идею изображения множеств с помощью кругов широко использовал Леонард Эйлер при решении целого ряда задач (известные круги Эйлера [4, с. 11]), основанных на работах выдающегося немецкого философа и математика Готфрид Вильгельм Лейбница. Лейбниц

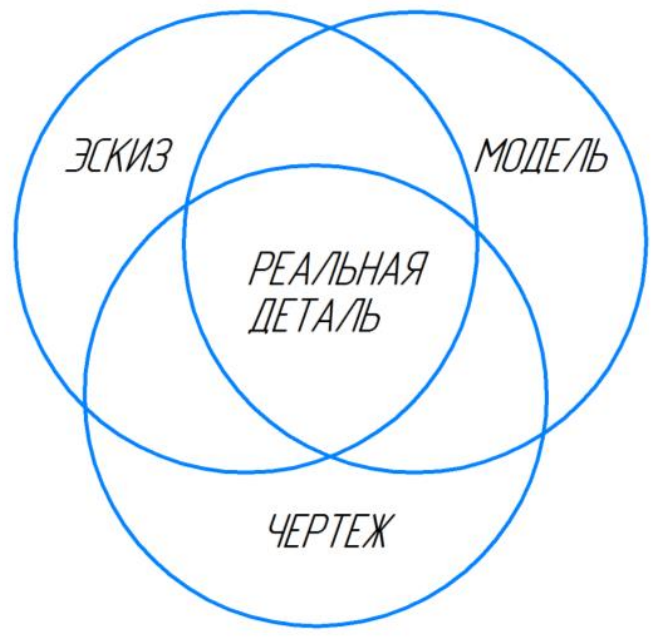

\section{Рис. 1. Структурная схема логических связей}

часто использовал линейные схемы, круги применял для геометрической интерпретации логических связей между понятиями. И действительно, не новые инженерные определения: эскиз, модель, чертеж, обретают смысловой контекст, когда завязаны на едином объединяющем компоненте - реальной детали.

Данная структурная схема может быть структурно-логическим блоком изложения учебного материала по методу педагога В.Ф.Шаталова [5], эффективность применения которой отражено в работе Н.А. Анисимовой [6]. 
Каждый этап работы направлен на достижение обучающимися определенных навыков, накопление умений, закрепленных компетенциями специальности.

На первом этапе задачей методики стало формирование комплекса навыков в создание эскиза изделия по реальной детали (рис. 2). Эскизы важный компонент при проектировании любых конструкций. Они используются в условиях производства, при ремонтных работах, при проведении научно-исследовательских и конструкторских работ. Исполнение эскиза позволяет отрабатывать умения нарисовать, а эскиз это именно рисование от руки, необходимое количество видов реальной детали с сохранением пропорциональности размеров на глаз. Данное упражнение дает возможность обучающимся тактильно ощутить реальное изделие, увидеть его геометрическую форму и, следовательно, наглядно понимать структуру детали. Эскизирование позволяет с легкостью изменять элементы рисунка с помощью ластика, развивая у студентов творческую мысль, художественное восприятие формы. Отсутствующая на данном этапе точность и четкость в построениях линий способствует развитию навыков формирования быстрого схематичного рисунка - чертежа. В тоже время эскиз отражает умение применять стандарты, согласно, которым должны выполняться виды детали ГОСТ 2.305-2008, нанесение размерных линий ГОСТ 2.307-2011, оформление основной надписи ГОСТ 2.104-2006.
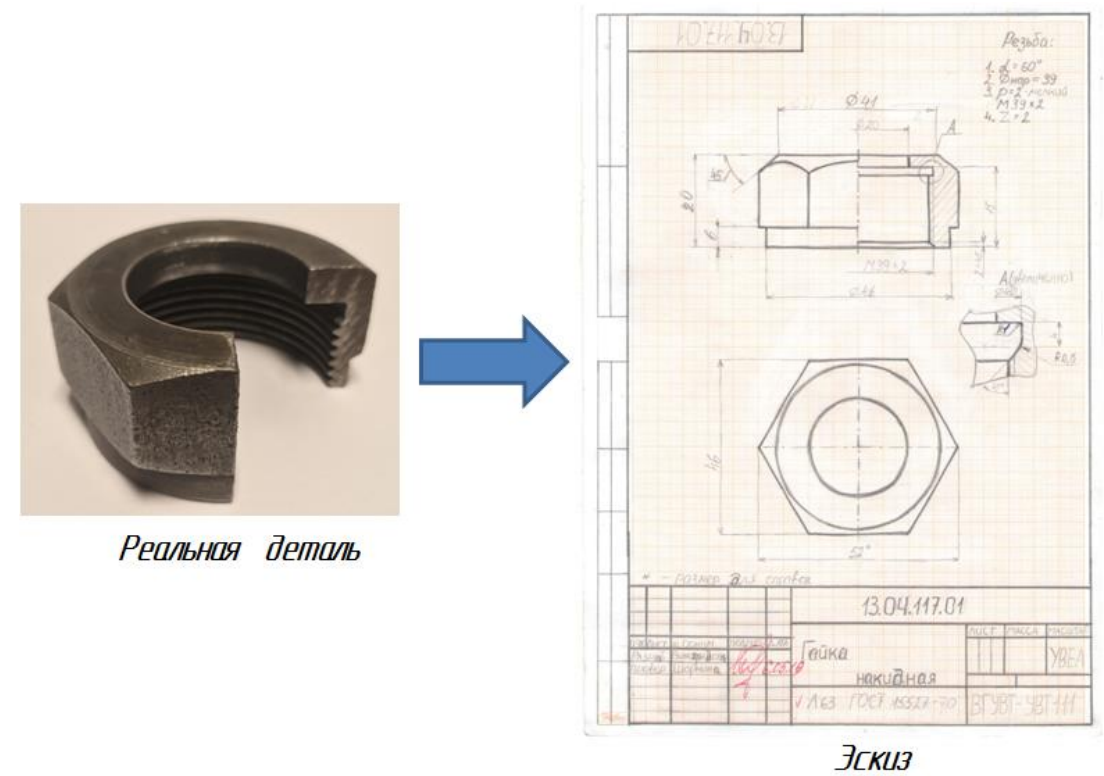

Рис. 2. Эскиз по реальной детали 
На данном этапе студент приобретает навыки обмера детали при помощи мерительных инструментов. Работа с мерительными инструментами дает возможность поэлементно изучить структуру детали, понять способы формирования ее будущей трехмерной модели. Овладеть умением выполнять графические построения конструктивных элементов, например, проточка на резьбе, представленная на рисунке 3. Используя справочную документацию определять параметры - размеры этих элементов. Формирование дополнительных видов на эскизе позволяет наиболее подробно изучить геометрическую форму и взаимное положение элементов.

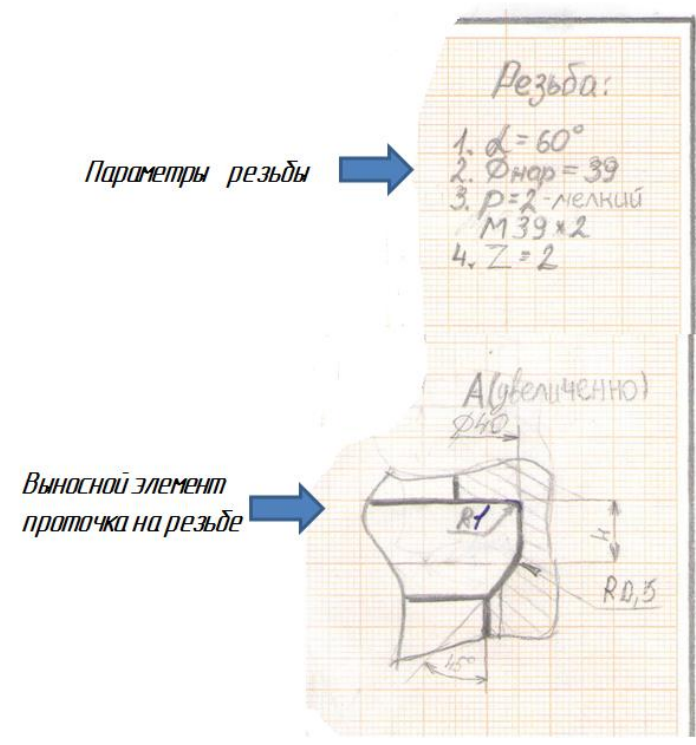

Рис. 3. Проточка на резьбе

Умение правильно определять геометрическую форму, конструктивную характеристику и параметрические признаки изделия позволяют выбрать точное обозначение изделия и конструкторских документов для него, а при наличии информационной системы с архивами конструкторских документов даст возможность быстро найти необходимую информацию для разработки будущей электронной модели и сопутствующей документации.

На втором этапе работы ставятся задачи вовлечь обучающихся в творческий процесс моделирования. Современное проектирование невозможно без электронной модели изделия. В терминах государственного стандарта [7] электронная геометрическая модель определяется как модель изделия, описывающая геометрическую форму, размеры и иные свойства изделия, зависящие от его формы и размеров. Как показывает опыт, этот этап 
упражнения дается студентам с удовольствием, позволяет визуализировать эскиз, выполненный на предыдущем этапе работы. Закладываются логические связи между созданием эскиза и трехмерной модели изделия (рис. 4).

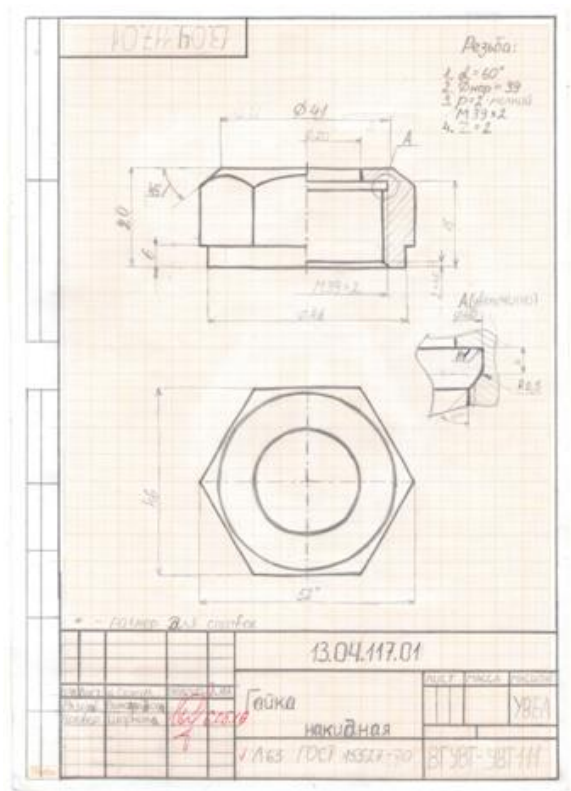

ЭГКUЗ

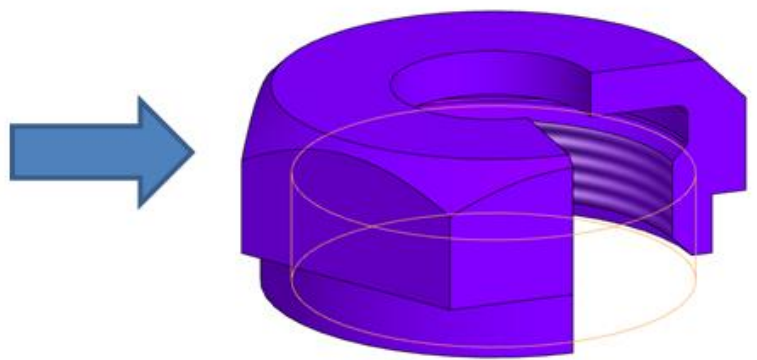

Эпектронная модель

Рис. 4. Модель по эскизу

Трехмерная модель исполняется с помощью систем автоматизированного проектирования. САПР обладают хорошим графическим инструментарием и как отмечено в исследовании [8] широко применяются в учебном процессе.

Данный этап логический, позволяет обучающимся выстроить последовательную структуру образования электронной модели изделия, дает возможность понимания формирования детали от заготовки к готовому продукту. Кроме формирования геометрической формы САПР позволяет придать свойства изделию, т.е. знакомит обучающихся с возможностью назначать материал, из которого можно изготовить деталь, выполнить расчет массо - центровочных характеристик на основе плотности материала и др. Приобретаются навыки и умения описания геометрических характеристик моделей, которые будут функциональны. Здесь зарождается связь инженерного происхождения «искусственного объекта» с реальным изделием. Именно на этом этапе геометрическое моделирование переходит в деятельностную инженерную геометрию. 
Третий этап работы систематизирует накопленный материал и отражается в виде готовой конструкторской документации. Создание полуавтоматического чертежа по электронной модели (рис. 5) активизирует у студентов конструкторскую деятельность к правильному оформлению выходной рабочей документации на изделие.

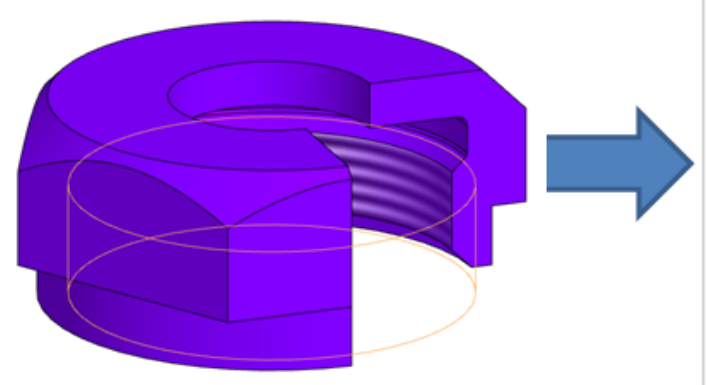

Эпекпронная модель

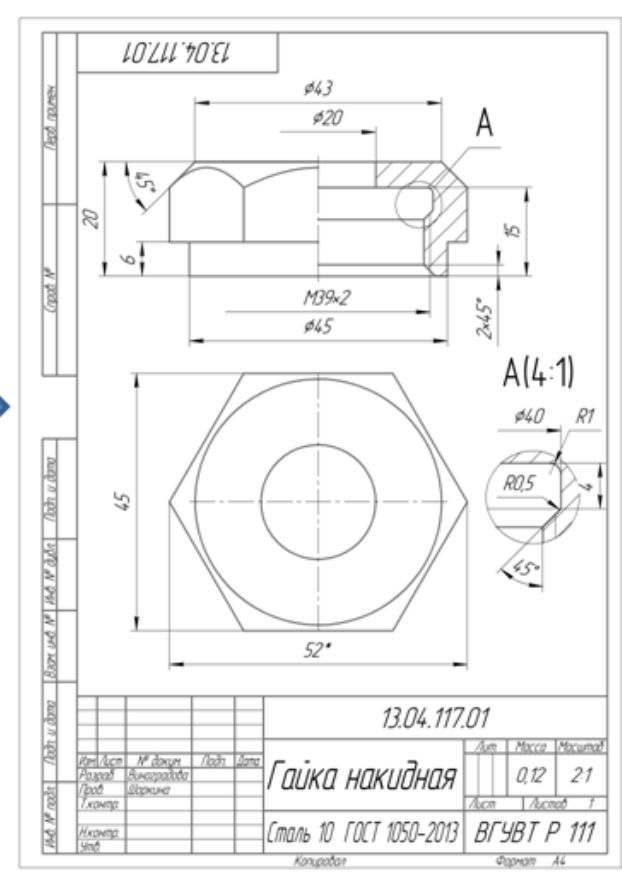

Черппеж

\section{Рис. 5. Чертеж по электронной модели}

Закрепляется понятие логических связей в структуре: реальная деталь эскиз - модель - чертеж. При этом интегрируются элементы графо геометрической и проектно-конструкторской подготовки в предметной области будущего специалиста [9].

Результаты экспериментальной проверки. Для установления эффективности разработанной методики подведены результаты усвоения материала группами студентов за пятилетний период ее применения. Результаты эксперимента представлены на рисунке 6. 


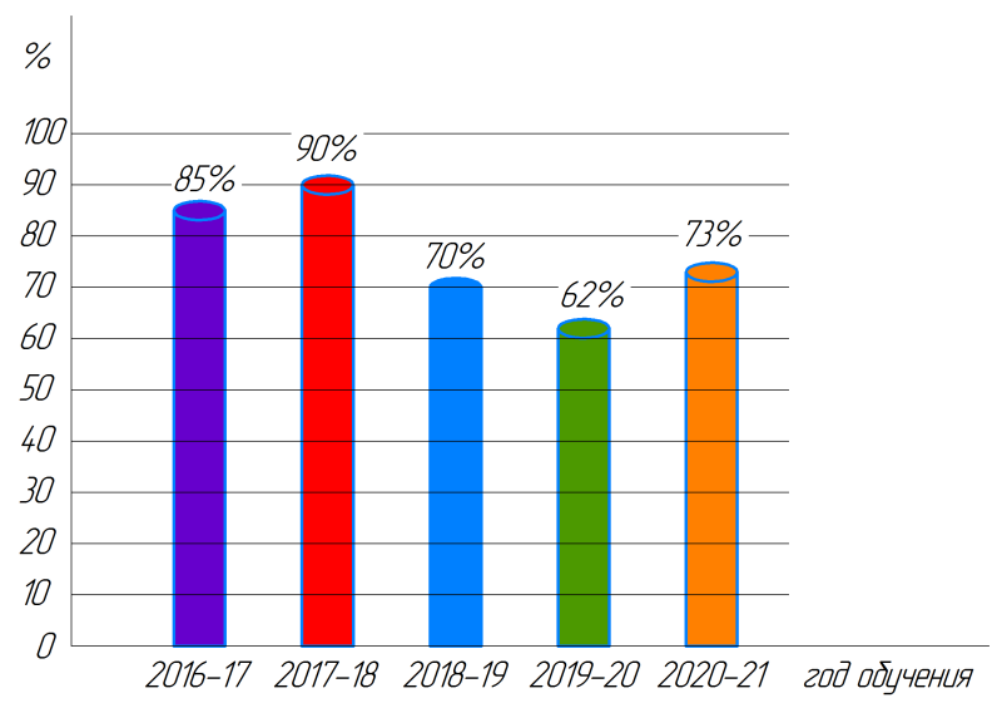

Рис. 6. Результат применения методики

Согласно полученным данным, несмотря на то, что в последние годы эффективность снизилась, применение данной методики можно назвать успешными. В данном случае спад эффективности является следствием низкого уровня знаний абитуриентов, поступающих на технические специальности, а так же формой дистанционного обучения, которая была необходимостью в 2020 году.

Выводы. Введение в учебный курс новой методики выполнения лабораторных работ позволяет проследить взаимосвязанные решения поставленной задачи и наглядно представить логические связи между этапами разработки изделия. Последовательно уяснить инженерные понятия и приобрести обучающимися необходимые навыки и умения в будущей специальности. Реализуется познавательная деятельность студента к восприятию графической информации.

\section{Список литературы}

1. Осадчук О.Л., Галянская Е.Г. Современные методологические подходы к исследованию педагогических процессов. Международный журнал прикладных и фундаментальных исследований. - 2016. - № 3-3. - С. 463-467; URL: https://applied-research.ru/ru/article/view?id=8756 (дата обращения: 12.12.2020). 
2. Пургина, Е.И. Методологические подходы в современном образовании и педагогической науке. Урал. гос. пед. ун-т. - Екатеринбург, 2015. - $275 \mathrm{c}$.

3. Егоров В.В., СкибицкийЭ.Г., ХрапченковВ.Г. Педагогика высшей школы: Учебное пособие. - Новосибирск: САФБД, 2008. - 260 с.

4. Кузичев А.С. Диаграммы Венна. История и применения. М.: Изд-во НАУКА, 1968. - 253 с.

5. Кондракова С.О. Опорные сигналы В.Ф. Шаталова средство активизации творческого подхода к учебному процессу // Известия Российского государственного университета им. А.И. Герцена. 2008. №65. С. 405.

6. Анисимова Н.А. Интенсификация процесса обучения начертательной геометрии студентов технических вузов посредством автоматизированной обучающей системы. // Успехи современной науки и образования. 2016. №12, Т.2. С. 57-61.

7. ГОСТ 2.052-2006 Электронная модель изделия. URL: https://docs. cntd.ru/document/1200045035 (дата обращения: 27.01.2021)

8. Анисимова Н.А., Шоркина И.Н. Анализ передовых графических систем для подготовки конкурентноспособных специалистов // Проблемы использования и инновационного развития внутренних водных путей в бассейнах великих рек. Труды конгресса «Великие реки» 2020. Выпуск 9, 2020.

9. Горнов А.О., Лепаров М.Н. Инженерная геометрия в образовательном контексте. Функциональный подход.

10. URL: http://dgng.pstu.ru/conf2017/papers/92/(дата обращ.: 20.02. 2021) 